\title{
Examining a multi-dimensional undeclared work via the REBUS-PLS
}

\author{
Claudio Quintano and Paolo Mazzocchi \\ Department of Management and Quantitative Studies, \\ University of Naples Parthenope, Naples, Italy
}

\begin{abstract}
Purpose - This article intends to investigate on the undeclared work (UW) by involving several features, which can be evaluated throughout a set of appropriate variables. The REBUS-PLS (Response Based procedure for detecting Unit Segments-Partial Least Squares) has been proposed in order to support policy decisions targeted to this heterogeneous scenario. The authors refer to Italy, due to the disparity of its territorial districts, but the conclusions can be extended to different European countries.

Design/methodology/approach - A total of 2,877,000 firms has been involved for empirical analysis. The manifest variables have been obtained by fixing both NACE codes and the NUTS2 level.

Findings - The analysis confirms that the model is suitable to evaluate the effects of the indicators connected to 'Labour force', 'Tax system', 'Non-Profit Organizations', and 'Migrants'. Special prominence has been dedicated to the labour inspections' features.

Research limitations/implications - If the management designs the policy actions by using the model proposed, a critical evaluation of the implications is needed, by focusing different perspectives and several weaknesses.

Practical implications - Assuming that the Italian regions are relatively homogeneous, results reveal no significant correlations to the UW, except for the taxes. In contrast, the involvement of the heterogeneity shows that the UW significantly depends on the changes of Labour force, Tax system and NPOs dimensions, in 11 out of 18 Italian regions. No clear evidence emerges from Migrants feature, which seems to have a negatively impact on the UW.
\end{abstract}

Originality/value - To the authors' knowledge, compared to the previous research papers, the analysis of the UW via REBUS-PLS and the mentioned manifest variables, has never been undertaken so far.

Keywords Undeclared work, Informal employment, SEM-PLS, Italian regions, Labour inspections, REBUS Paper type Research paper

\section{Introduction}

In recent years, different literary contributions have begun to contest the dualism between the formal and informal economy. The International Labour Organization Conference (ILO, 2014, 2015) described the informal economy as all economic activities not covered (or insufficiently covered) by formal arrangements. A large number of perspectives has been proposed to describe the informal aggregate in the contemporary global economy, and different dimensions connected to the formal and the informal contexts have been considered (Williams and Windebank, 2005; Williams et al., 2013; Gialis and Leontidou, 2014). Due to the hidden nature of the phenomenon, comparative data are not available, and figures are very often based on different definitions and estimation techniques. Various studies revealed that informal economy is an extensive and expanding phenomenon, and Charnes (2012) and

(C) Claudio Quintano and Paolo Mazzocchi. Published by Emerald Publishing Limited. This article is published under the Creative Commons Attribution (CC BY 4.0) licence. Anyone may reproduce, distribute, translate and create derivative works of this article (for both commercial and non-commercial purposes), subject to full attribution to the original publication and authors. The full terms of this licence

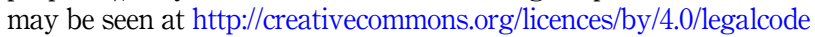

The authors are grateful to the Editor and two anonymous referees for their helpful reviews and suggestions.

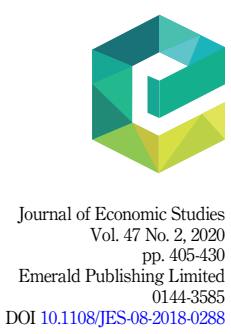


JES

47,2
Eurostat (2014) underlined that it includes several kinds of informal employment. Concerning the papers which presented an exploration of different descriptions of informal employment, Woolfson (2007a), Williams and Padmore (2013) and Williams and Shahid (2014) highlighted that prevalent literature considers formal and informal employment as being mutually exclusive instead of taking into consideration that these kinds of job can occur simultaneously. According to the definition proposed by Slemrod and Weber (2012) and Schneider and Williams (2013), the current paper considers the informal economy as those legal activities not declared to the Authorities for taxes, social security and/or labour law purposes.

This research attempts to contribute to the informal economy domain in several ways. The primary objective is to investigate on the most prominent determinants of undeclared work in Italy. The Italian scenario represents a good 'case study' due to the disparity of its territorial districts, at the NUTS2 level (regions)[1]. In more detail, the Italian regions are characterised by a wide dissimilarity in the unemployment rates, a high share of NEETs (young people Not in Employment, Education and Training), a large number of atypical employment contracts (Eurostat, 2016). Various features have been considered in the present analysis, and extensively discussed through the indicators connected to these characteristics. One example refers to the migrants, even though it is very difficult to take into account the impact on informality of thousands of immigrants in Southern Europe, especially in Italy. Special prominence has been dedicated to the labour inspections. The importance of labour inspections has always been recognised internationally, since the ILO was founded in 1919 (ILO, 2014).

Secondly, an analysis of appropriate NACE codes is proposed as a mean to examine the undeclared work[2]. This assumption (which is connected to the activity/job/enterprise-based perspectives widely debated further) is adopted with the aim of fixing several dimensions. The usage of data from different sources is also presented.

Thirdly, this article provides an innovative methodological framework based on a structural model. The authors suggest the usage of the REBUS-PLS (Response Based procedure for detecting Unit Segments-Partial Least Squares) technique, an analytical strategy proposed by Esposito Vinzi et al. (2008). This approach involves the component-based estimation of the Structural Equation Models (SEMs), by means of PLS-PM (Path Modelling). The theoretical model examines the causal relationships among several latent dimensions, each measured throughout a number of observable indicators (also called manifest variables). Usually, the SEM-PLS refers to the full set of data, by assuming a relatively (often unrealistic) homogeneity that sometimes can result in incorrect conclusions. In contrast, this article considers that an (unobserved) heterogeneity in the informal scenario exists, and the manifest indicators were chosen as they have the most comprehensive data availability.

The Italian National Statistical Institute (ISTAT, 2018) and De Gregorio and Giordano (2015) highlighted that recent research on the informal employment has progressively moved from the mere estimation of general indicators concerning the incidence of this phenomenon, toward more explicit insights into its multifaceted and heterogeneous nature. Based on a 2013 Euro barometer survey, the European Commission (2017a) emphasized the impact of heterogeneity on informal driving forces in Europe. Therefore, in the authors' opinion, the clusters of Italian regions (a priori unknown) having a similar behaviour pattern can be identified, and the impact of the different latent dimensions can be estimated. To the authors knowledge, this attempt to analyse the informal aggregate via REBUS-PLS and the mentioned manifest variables, has never been undertaken so far.

From a policy point of view, this investigation could offer useful insights in order to support policy decisions targeted to evaluate the determinants of the informal phenomenon. Even though this research refers to the Italian scenario, the model can be extended to different European countries, and European Commission (2016) underlined the persistent need for effective social and labour market policies specifically directed to tackle the undeclared work. 
As for the remaining contents of this article, the following section reviews the relevant theoretical background connected to the informal employment and the Italian scenario. Section three discusses several specifications related to the dataset, and section four refers to the analytic strategies. The last section combines results and discussion.
Examining undeclared work via the REBUS-PLS

\section{Theoretical background}

The definition of informal economy considers different perspectives. In a similar way, the workers' involvement also results from diverse outlooks. These features-and the heterogeneity among the Italian regions-can be briefly described as follows.

\subsection{Formal versus informal: definitions and perspectives}

The theoretical informal sector literature proposed by ILO $(2014 ; 2015)$ attempted to reduce the confusion among the informal sector and different System of National Accounts' underestimations [3]. In fact, even though substantial literature exists on single aspects of the informal economy, the subject is still quite controversial. Macroeconomic pictures of the informal economy, as a share of labour force and/or production (Gross Domestic Product, GDP), are continuously estimated by economists and statisticians, and are used for policy purposes. Following a pure National Accountant statisticians' perspective, the individual countries' National Accounts must not be affected by institutional peculiarities (OECD, 2012). Therefore, a standard approach to measure each clusters included in the Non-Observed Economy is required. In September 2014 several modifications have been adopted in the standard measurements with the aim of including the size of EU Member States' illegal production (Eurostat, 2018a). Despite this, Dell'Anno et al. (2018) and Benkraiem et al. (2019) noted that several definitions of the informal, underground, non-observed and/or shadow economy still coexist in the existing economic literature.

In general, the definition of the boundaries of 'irregularity', the increasingly fading borders between regular and irregular labour, the large number of linkages between formal and informal activities, the enterprises' behaviour which involve both informal and formal employees make the informal scenario very intricate. As a result, the research on the informal employment has gradually shifted from the production of a synthetic indicator regarding the incidence of this phenomenon, toward a multidimensional approach, which can be useful for policymakers. OECD (2003) analysed the circumstances in which the irregular work derives from a misrepresented formal expressions of regular work and falls within the area of the 'grey economy' aggregate. Among others, the problematic distinction among the various categories of informal employment was investigated by Renooy (2007) and Hatton (2015). William and Padmore (2013) presented a detailed overview of the different 'enterprise-based', 'jobs-based' and 'activity-based' informal employment definitions, in order to distinguish informal from formal employment. With the aim of analyzing the undeclared payment to formal employees in addition to their formal wage, these authors stressed that several circumstances are not covered neither by enterprise-based definition (since the work is performed in a formal enterprise) nor by job-based definition (since the workers are employed in a formal job). OECD (2003; 2012) highlighted that enterprise and jobs-based definitions dominated the literature on informality in developing and emerging economies, while the activity-based definition is the most frequently adopted methodology in developed countries. Since the usage of specific NACE codes is proposed, the present research refers to the activity-based perspective.

With regard to the people's involvement in undeclared work, prevalent literature suggests two different strands of thoughts. The first point of view was proposed by Sassen (1997) who referred to the 'structuralist perspective'. It considers workers involvement in the informal economy as a result of a 'forced exclusion' from the formal economy. Therefore, the informal 
JES

47,2

408

economy provides the most significant source of income for those workers. From the second perspective, informal workers 'voluntarily exit' from the formal economy due to several reasons. For instance, the neo-liberal theory emphasizes on the contribution of the 'rational economic decision'. As a consequence, the participation in the informal economy results from a rational economic strategy pursued by workers versus institutional constraints and regulations, since the informal economy is considered as a resource for potential benefits, including avoidance of taxes. If one assumes this perspective, the policy approach must be targeted to rational economic actors who compare the cost/benefit ratio of involvement in the undeclared work (one might think about the probability of detection and punishment as proposed by Allingham and Sandmo, 1972). In this scenario, Governments can consider several discouraging policy approaches (and/or deterrence) aimed to increase the actual (and/ or perceived) costs and risks of detection of participating in the informal economy (Richardson and Sawyer, 2001). The 'exit perspective' is also argued by research papers which refer to the 'social actor theory' (Gërxhani, 2004). This scheme involves the 'formal' codified laws and legal regulations (the so called 'formal institutions') and the society's 'informal' institutions (which refers to the '... socially shared rules, usually unwritten... created... outside of officially sanctioned channels' as proposed by Helmke and Levitsky, 2004). In this perspective, an asymmetry between the formal and informal institutions exists, and people are involved in the informal sector due to the fact that they perceive their behaviour as socially legitimate. Informal work undertaken for close social relations (and/or connected to the intricate mix of multiple jobs scrutinized by Nelson and Smith, 1999) is also included (Williams et al., 2016). In this situation, the policy approach to tackle the informal economy is different, and it can attempt to reduce the above-mentioned asymmetry instead of considering deterring measurements. In the present article a rational economic standpoint is adopted.

In addition to the dichotomous 'exclusion' versus 'voluntarily' perspectives, Williams and Bezeredi (2018a) focused on a 'dual informal labour market', in which formal workers receive both the declared and undeclared wages from their formal employers. The configuration of the local labour market, legal entry barriers (such as environmental regulations), licensing requirements, bureaucratic delays, etc. exacerbate the informal composite scenario. As a consequence, the attitude towards tax compliance decreases, while the reasons for firms to operate outside the formal sector increase. Webb et al. (2009) and Williams and Bezeredi (2018b) focused on the entrepreneurs' point of views concerning the acceptability of being involved in the informal sector.

\subsection{Italian scenario}

As already stated in the introduction, Italy is characterized by significant differences among its regions, and the labour market has recently widely changed. From legislative point of view, the Law n. 196/1997 (the so called 'Pacchetto Treu'), the Law n. 30/2003 (also known as 'Legge Biagi'), the Law n. 92/2012 (Legge Fornero) and Law n. 183/ 2014 (Jobs Act) represent the main reforms. Structural unemployment and persistent stagnation of productivity are particularly strong in several Italian regions (Eurostat, 2015). Job opportunities are unevenly distributed among the labour force, and the marginalization of specific segments of the working population has increased especially in Southern regions (Directorate-General for Internal Policies, 2014). The regional GDP, which is usually used to measure macroeconomic activity and growth, presents lowest levels in the Southern Italian regions.

Since the authors assume that an unobserved heterogeneity in the data exists, it is important to analyse the informal phenomenon through different models for dissimilar Italian macro-economic areas (clusters of regions). The sample of the Italian regions has been fixed as a function of the data availability. Consequently, only eighteen out of twenty regions 
constituting the second NUTS Italian administrative level have been considered (Sicily and Trentino-South Tyrol have not been included). Focusing specifically on the indicators involved in this paper (and widely analysed further), the first measurement refers to the unemployment rate, which in the South is more than double compared to unemployment rates of their corresponding peers living in the North (ISTAT, 2018). Considering the NEETs, in the South of Italy, one out of two young people are NEETs, while in the North and in the Centre, only one out of four belongs to this category. Among other, interesting findings between Italian inactive people and irregular workers are presented by Boeri and Garibaldi (2002) and by De Gregorio and Giordano (2015). With regard to the share of young people who attained at least a 3-ISCED level of education, in 2016 they were more than 80 percent in the North and in the Centre, while in the Southern regions were around 60 percent (ISTAT, 2018). Furthermore, the transition from the educational system (school or university) to work is very different among the Italian regions. As for taxes, even though Central Government retains a significant important rule, increasing influence has been decentralized to Regional Governments. Concerning the number of workers involved in the Non-Profit Organizations (NPOs), ISTAT (2018) report highlighted that they increased of 170 percent during the last ten years, although this rate is different among the regions. As mentioned in the introduction, the impact on informality of thousands of immigrants in Southern Europe, especially in Italy, can be only approximately estimated. Olivieri (2012) analysed the increasing Italian inflow of immigrants (both documented and undocumented) during the last 20 years. This author noted that in the North and in the Centre of Italy immigrants were generally engaged in industrial activity (and services related to industry) and commerce, while in the South of Italy they were usually (irregularly) involved in agricultural and building sectors. With regard to the labour inspections, as a consequence of the substantial policy changes adopted in 2016, the Italian system has been widely modified. A supervisory agency for monitoring the inspection activities (the General Labour Inspectorate) has been created as a consequence of the new law structure (Jobs Act). Before then, the three Italian institutions responsible for coordinating labour inspection activities were the 'Ministry of Labour and Social Policy', the 'General Directorate for Inspection Activities' (DGAI) and the 'National Institute of Social Security' (INPS; Fasani, 2011). In addition to them, the 'Italian Government Agency for the Insurance Against Work-Related Injuries' (INAIL) performed different kinds of labour inspections, connected to the the work-related accidents.

At the EU level, the persistence of significant regional disparities also results from the regular Eurostat (2018b) and OECD (2016) production of regional statistics, mainly at the NUTS2 level. Therefore, this analogy between the Italian and European scenarios represents a significant assumption in order to extend the model to other European countries.

\section{Data description}

As mentioned above, this article considers the Italian regions, and it focuses on the year 2015. A total of 2,877,000 firms has been involved for empirical analysis. Data provided by ISTAT has been used, as well as data disseminated by Eurostat, Bank of Italy and the General Labour Inspectorate. The manifest variables have been obtained by fixing both the 'spatial' dimension and the 'economic' dimension. The 'spatial' dimension depends on the NUTS2 level (Italian regions), while the 'economic' dimension is connected to the NACE codes. This assumption is necessary in order to assess several manifest indicators, such as the most prevalent (seven) NACE sectors involved in the labour inspections[4]. According to this assumption, a total of 191,000 labour inspections has been considered. The model considers only one endogenous variable, the Undeclared Work $(U W)$ which can be estimated by using four latent (exogenous) determinants. Among the numerous determinants of the $U W$, the following have been identified as relatively more significant than others: Labour force
Examining undeclared work via the REBUS-PLS 
JES

47,2

characteristics, Tax system, Non-Profit Organization, and Migrants. As for the relationship stated by the authors that one endogenous variable $(U W)$ depends on four exogenous latent variables, several specifications on the assumptions of the SEM-PLS are widely discussed in the next sections.

\subsection{The NEETs}

The statistics traditionally used to describe labour markets are currently focusing on the market participation of younger people, and on the increasing share of the NEETs. This segment of population was first identified (and analysed) in the eighties, in the United Kingdom. An all-encompassing analysis of the NEETs determinants should require an extensive exploration which is beyond the aims of this research. Overall, the NEETs refer to the economically inactive (or unemployed) people who are not in training or education, according to the definition proposed by the EU Labour Force Survey-LFS (Eurostat, 2017) and by the ILO (2016). This cluster has been increasingly considered in several research articles, and this investigation has been recently complicated by the emerging new, and less clear, patterns. The growing share of students, working at the same time, and the rising proportion of people in employment who are also studying, constitute two examples. Among others, in order to describe the difficulties of young people in the labour market, Martin et al. (2007), Bruno et al. (2014) and Duell et al. (2016) analysed the long-term unemployment in the EU. Furlong (2006) presented several policy measurements targeted to significant criticisms of the NEETs' sub-clusters. In general, NEETs are potential workers, and their inactivity produces several disadvantages, which usually encourage long term unemployment, depression, and further extra social costs for the entire society (OECD, 2016; Eurostat, 2016).

\subsection{Educational skills}

Usually, the informality decreases moving up on the education pyramid, reaching its lowest level for highly skilled workers, who enjoy greater job security and benefits in the formal economy. ILO (2018a) underlined that nearly 75 percent of workers involved in informal employment had a primary education as the highest educational level. Cappariello and Zizza (2010) attempted to analyse the link between education skills and $U W$, extensively focusing on the 'voluntarily exit' perspective. They argued that the relationship between education level and $U W$ is clearly different according to the different assumptions. If one assumes that the level of education is an indicator of one's involvement in the informal sector, consequentially policymakers could try to introduce policies to improve the level of education. From a different perspective - for instance when rational actors evaluate the cost/ benefit ratio of involvement in $U W$ and the above-mentioned assumption fails - work in the informal sector could be chosen voluntarily by workers as an alternative to regular employment. If this standpoint prevails, the implications of the level of education are less clear. A different problem refers to the over-education, but an extensive exploration of it is beyond the aims of the current research[5].

According to Eurostat (2016) perspective (which highlighted a positive correlation between the rates of employment and of high educated people) and ILO (2018a) conclusions (which underlined the relationship between the increase in workers' level of education and the decrease in the share of informal employment in EU) in the present research the authors assume a negative correlation between $U W$ and educational skills. Since this assumption refers to an indicator which represents the percentage rate of people who completed the tertiary education, the changing of the direction of this relationship is necessary in the current article (and it is widely analysed further). Therefore, the scale of this indicator must be reverted, with the aim of verifying that the decrease of the workers' education level is positively correlated with the $U W$. 


\subsection{Part-time, fixed-term contracts and volunteer work}

An important labour market trend in the recent years is the growth and the diversification of non-standard contractual arrangements, which are replacing full-time employment. One of the most significant forms of non-standard employment consists of temporary employment, usually fixed-term contracts and project-based works characterized by a very short employment relationship, often informal (ILO, 2018c). A significant increase of several apprenticeship schemes, part-time employment, temporary and atypical contracts have introduced radical innovations in the job contractual forms, and have reduced the level of employment protection (Eurostat, 2016). The incidence of these contracts is especially common among individuals working in agriculture, construction, hospitality, sports and spas. It differs significantly between men and women, and it increase especially among young people. This over-representation of young people in temporary work reveals both (1) changes in labour market demand, and (2) a structural modification of the cultural norms as well (Farr-Wharton et al., 2015). In several EU member States, young people prefer fixed-term contract due to the fact that they are involved in educational training. In contrast, this might not be a personal choice for many people of different countries, thus generating the risk that people stay tied up in a long series of temporary contracts. Another relevant feature which needs to be considered refers to volunteer workers, particularly relevant in institutions such as the Non-Profit Organizations (NPOs). The NPOs have different purpose than making profit, and they are usually devoted to a particular social cause. Different laws regulate their compliance with the each national tax system. In general, volunteer workers do not receive any form of remuneration for the services they provide, although they can receive a limited amount of money to reimburse their expenses. When they receive reimbursements beyond the scope of regulations and labour law, this could be regarded as $U W$. Vos et al. (2012) widely stressed the potential distortion connected to the payment of volunteers in NPOs, throughout 'not appropriate' reimbursement schemes.

\subsection{The tax system}

An extensive analysis of the features connected to tax evasion, tax avoidance, tax compliance, tax gap and tax morale has not been included in the present article. Nevertheless, an increasing literature is focusing on these widely debated issues. While the $U W$ deprives state budget of substantial amount of resources, an efficient tax system needs to be accepted by taxpayers. Schneider and Enste (2013) underlined that the distortion of the overall tax burden is a major concern for the economists. The European Commission (2017b) presented an overview on the taxation in the European Union. This Report discussed tax reforms in the EU member States and highlighted some examples of good practices, stressing that the reduction of the tax burden on labour could support the employment. In the present article, both the tax burden on the households and on the firms have been involved, at NUTS2 level.

\subsection{The labour inspections}

The ILO Conventions n. 81 and n. 129 defined the profile of the labour inspection systems[6]. Overall, most of the previous researchers studies argued that when the audit activity increase, the $U W$ decreases (De Juan et al., 1994; Blackwell, 2002). Several outlooks can be considered: Piore and Schrank (2008) investigated on the impact of deterrence approaches on the non-compliance; OECD (2010) presented a summary of factors influencing the taxpayers behaviour; Weil (2008) analysed several labour inspections' features among ILO countries. Williams and Lansky (2013) stated that policymakers have several main theoretical options to deal with informality:

(1) 'doing nothing', which has potential negative effects on businesses, informal workers, customers and governments;
Examining

undeclared work via the REBUS-PLS 
JES

47,2

(2) 'deregulation option', which proposes to reduce the taxes and state regulations which potentially disincentive the formalization;

(3) 'promoting formalization', throughout several policy measures.

The ILO Resolution concerning 'decent work and the informal economy' sustained that an international policy consensus has already been reached on the 'formalization' option, even though it depends on the informal features of each country. In general, prevalent literature distinguishes between 'hard' and 'soft' compliance approaches. The first standpoint assumes that actors in the informal economy are 'rational economic agents', consequently the perspective aims to modify the cost/benefit ratio of the informal involvement, and deterrence measurements can be used as a leverage. Economic literature connected to the empirical evidences of the above-mentioned approaches indicates mixed outcomes. Several research papers confirmed a positive correlation between compliance and risks of detection (Mazzolini et al., 2017). In contrast, Murphy (2005) noted that increasing the risks of detection does not reduce non-compliance, while Schneider and Enste (2013) did not find significant association. Feld and Frey (2007) provided support for ambiguous impact of deterrence on tax compliance, and Di Porto (2011) noted that in several NACE categories the labour inspection activity induce counterproductive reactions. OECD (2012) attempted to provide an overview of the recent advancements to perform the 'hard' approach. The second (soft) approach considers the 'indirect' policy control instead of a 'direct' one. In this case, policy measurements should be targeted to inform people on the benefits of formality and/or to promote compliance, etc. (Pires, 2008).

Considering the manifest variables quoted in the current research model, two indicators represent the results of the inspection activity. Authors performed a preliminary data analysis and noted that the number of labour inspections increases with the number of labour law violations[7]. One main reason is that, despite the complexity highlighted by Vega and Robert (2013) connected the different entities which coordinate the Italian labour inspection activity, the GLI's efforts 'to direct' the inspectors against the firms involved in the 'most vulnerable' NACE sectors resulted successful (GLI, 2018). Consequently, these manifest variables represent 'control' variables in the model, and a positive correlation is expected between the $U W$ and these indicators. The GLI's report (2018) also emphasized that the number of Italian inspections is widely divergent among the regions. ILO (2013b) highlighted the persistence of several significant weaknesses connected to the inadequate number of labour inspectors in Italy, compared to the real needs. Furthermore, the ILO report underlined that differences in the EU inspectorial policies can have diverse causes, mainly influenced by policy options and available resources.

\subsection{The contribution of the migrants}

During the recent years the inflows of migrants for economic reasons and of refugees fleeing conflicts and poverty increased. Eurostat, OECD and several National Statistical Agencies provide data of migrant labour market statistics. Nevertheless, ILO (2018b) has recently proposed the 'Guidelines concerning statistics of international labour migration', since it highlighted that 'international standards on definitions and methodologies for measurement the labour migration flows' are missing. This effort to improve the labour migration statistics is needed to implement effective labour migration policies and to achieve several Sustainable Development Goals.

There is a considerable amount of literature on how immigrants contribute to the labour market of their host country, and previous studies shows mixed results of the relationship between migrants and $U W$. On one hand, the contribution of the migrants can be considered for the positive impact on the economic growth and for encouraging flexible labour market. The European Commission (2017a) highlighted that people who relocate for 
economic reasons significantly supported the EU's labour force. The same report highlighted that migrants coming from countries outside the EU usually cover low-skilled and insecure jobs, especially because the educational and professional qualifications acquired by foreigners are not recognized in the hosting country, and therefore considered invalid in accessing into the labour market.

On the other hand, migrants can be analysed referring to the contribution to the precarious employment (Woolfson, 2007b; McCollum and Findlay, 2015). An additional problem refers to the illegal immigration, which is a controversial issue in political debates across Europe and beyond. The available migration estimates generally does not cover irregular worker migrants (ILO, 2018c). Reyneri (2004) highlighted that migrants contribute to $U W$ because they are particularly disposed towards accepting, whether through constraint or otherwise, this kinds of job. Maroukis et al. (2011) observed that both regular and undocumented immigrants provide a significant source of $U W$, although the second category represents the major source due to limited rights in the host country.

\section{Analytical strategies}

As pointed out in the introduction, this article refers to REBUS-PLS procedure. In contrast to the usually validated 'homogeneity' of the data, the authors assume that unobserved 'heterogeneity' in the data exists. It can be approached by considering the REBUS procedure, in order (1) to identify the clusters of units having similar behaviour pattern, and (2) to estimate the impact of the different latent constructs (Trinchera, 2011). A large amount of studies has empirically compared the SEM-PLS approach and the different 'covariancebased' LISREL type approach. An extensive evaluation of the SEM-PLS and SEM-LISREL approaches was proposed by Reinartz et al. (2009). Both these methodologies have been used in order to estimate the informal sector, and different sub-clusters of the non-observed economy (Schneider and Enste, 2013; Quintano and Mazzocchi, 2013). In the SEM-PLS, an iterative algorithm (a sequence of ordinary least squares regressions) separately solves out the blocks of the 'measurement' (or 'outer') model and then, in the second step, estimates the path coefficients in the 'structural' (or 'inner') model. The appendix gives more technical details. Hair et al. (2017) discussed on recent advancements of this methodology, bringing up several advantages, disadvantages and specifications.

\subsection{SEM-PLS}

The SEM-PLS can be specified in terms of a set of matrix equations, which is based on a well defined path diagram in order to escribe the relationships between the different dimensions (Singla et al., 2018). The path diagram shown in Figure 1 visually indicates the relationship stated in the SEM-PLS procedure: one endogenous variable $(U W)$ is estimated by using four exogenous determinants. The authors postulate that the $U W$ depends on characteristics connected to (1) Labour force, (2) Tax system (TAX), (3) Non-Profit Organizations, and (4) Migrants.

The group of determinants consists of latent variables which have been estimated by using a set of specific indicators. These indicators have been calculated as percentage rates, for each Italian region (therefore at the NUTS2 level). To describe the statistical significance of the relationship between the $U W$ and its latent dimensions, the authors express the following general equation:

$$
\mathrm{UW}=f(\text { Labour Force, Tax, NPOs, Migrants })
$$

Details about manifest variables' codes, definitions, summary statistics and data sources are provided in Table I. The Labour force is the first latent dimension mentioned in the model.
Examining undeclared work via the REBUS-PLS 


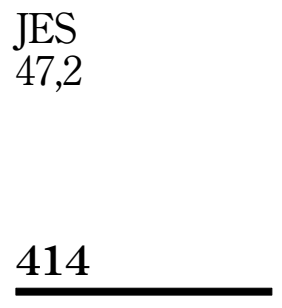

Figure 1. Path diagram

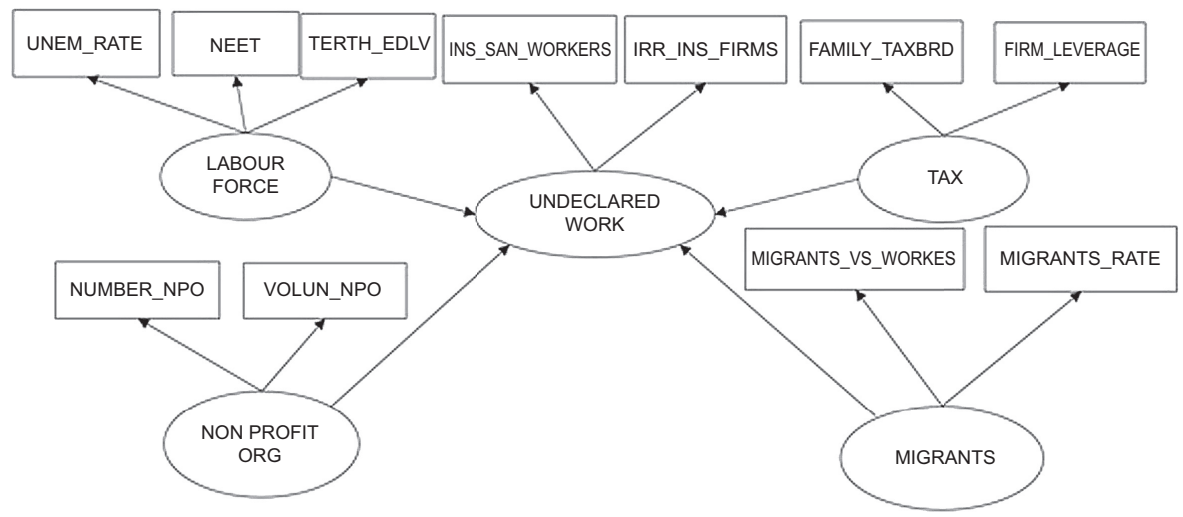

This first block includes three manifest variables. It specifically refers to the unemployment rate (Unem_rate, people aged 15-74). The manifest variable connected to the percentage rate of NEETs is also included (NEET), as well as the indicator connected to the educational attainment level (Terth_edlv). This latter indicator refers to the percentage rate of people who completed the tertiary education.

The second latent variable, the Tax system, encompasses several key features, serving as an essential component to deal with the $U W$. This block includes a manifest indicator (Family_taxbrd) which represents the tax burden on the resident households. The value is calculated as a percentage variation compared to the average national rate. The Tax system also includes the tax burden on the firms (Firm_leverage).

The NPO construct contains two manifest indicators. The first dimension (Number_npo) refers to the percentage increase of the number of NPOs, from 2005 to 2015. The second one (Volun_npo) denotes the percentage increase of the number of voluntaries in the NPOs, from 2005 to 2015.

The Migrants construct refers to other two dimensions. The first (Migrants vs workers) considers the share (expressed as percentage ratio) of total immigrants compared to the number of workers in the NACE sectors included in the analysis. The second indicator considers the incidence of immigrant component compared to the average national rate (Migrants_rate). One expects a positive sign of the coefficients of these four constructs.

The last two manifest indicators can be grouped in order to consider the labour inspection features. The first one (Irr_ins_firms) considers the share of non-compliant labour inspections, compared to the total number of the firms. The second dimension (Ins_san_workers) refers to the share of penalties imposed, compared to the number of workers. The two manifest variables mentioned above represent the results of the inspection activity, and-as extensively debated in section 3.5 - a positive correlation is expected between the $U W$ and these indicators. Throughout the model proposed, the authors intend to verify if there is an empirically strong interaction among the $U W$ and its indicators.

4.1.1 Outer model. In SEM-PLS approach the 'outer', 'inner' and overall models need to be validated. As for the outer model assessment, in a reflective approach, the blocks of the manifest variables have to be 'homogeneous' and 'one-dimensional'. In order to check the 'homogeneity' of the blocks, Table II reveals satisfactory values of the main indices (the Cronbach's alpha and the Dillon-Goldstein's rho-also known as composite Jöreskog's rho), since they are larger than the generally accepted threshold (0.7). In regard to the outer weights, if several indicators had positive weights, while others had negative ones, this would have a negative impact on the Cronbach's alpha and Dillon-Goldstein's rho (both the indices 


\begin{tabular}{|c|c|c|c|c|c|c|}
\hline Codes & Description [sources] & Minimum & Maximum & Mean & SD & Exammin \\
\hline Unem_rate & $\begin{array}{l}\text { Percentage rate of unemployed } \\
\text { people (Eurostat's definition) [I] }\end{array}$ & 12.200 & 42.600 & 22.589 & 10.076 & work via the \\
\hline Neet & $\begin{array}{l}\text { Percentage rate of NEETs } \\
\text { (Eurostat's definition) [III] }\end{array}$ & 10.789 & 39.912 & 21.134 & 8.596 & \\
\hline \multirow[t]{2}{*}{ Terth_edlv } & $\begin{array}{l}\text { Percentage rate of people who have } \\
\text { completed the tertiary educational } \\
\text { attainment level (Bachelor's, }\end{array}$ & 0.028 & 8.081 & 4.768 & 1.857 & 415 \\
\hline & $\begin{array}{l}\text { Master's and PhD levels of } \\
\text { education) [III] }\end{array}$ & & & & & \\
\hline Number_npo & $\begin{array}{l}\text { Percentage increase of the number of } \\
\text { the Non Profit Organizations from } \\
2005 \text { to } 2015[\pi]\end{array}$ & 2.755 & 172.110 & 49.707 & 37.229 & \\
\hline Volun_npo & $\begin{array}{l}\text { Percentage increase of the number of } \\
\text { the voluntaries of the Non-Profit } \\
\text { Organizations from } 2005 \text { to } 2015 \text { [T] }\end{array}$ & 22.237 & 248.236 & 68.996 & 52.632 & \\
\hline Family_taxbrd & $\begin{array}{l}\text { Tax burden of the resident } \\
\text { households (percentage variation } \\
\text { compared the average national rate) } \\
\text { [II] }\end{array}$ & -31.075 & 26.619 & -4.189 & 13.624 & \\
\hline Firm_leverage & Firms' leverage (Percentage rate) [II] & 34.900 & 59.500 & 50.383 & 5.597 & \\
\hline Migrants_vs_workers & $\begin{array}{l}\text { Percentage ratio between the total } \\
\text { immigrants and the number of } \\
\text { workers }[\mathrm{I}]\end{array}$ & 23.627 & 61.607 & 40.101 & 9.914 & \\
\hline Migrants_rate & $\begin{array}{l}\text { Percentage rate of total immigrants } \\
\text { (percentage variation compared to } \\
\text { the average national rate) }[I]\end{array}$ & -96.466 & 387.682 & 13.290 & 122.852 & \\
\hline Ins_san_workers & $\begin{array}{l}\text { Percentage rate of the punitive } \\
\text { sanctions compared to the number of } \\
\text { workers [I, IV] }\end{array}$ & 0.119 & 1.008 & 0.423 & 0.252 & \\
\hline Irr_ins_firms & $\begin{array}{l}\text { Percentage rate of the irregular } \\
\text { inspections compared to the number } \\
\text { of firms [I, IV] }\end{array}$ & 0.995 & 5.727 & 2.667 & 1.369 & $\begin{array}{r}\text { Table } 1 . \\
\text { Manifest variable's } \\
\text { codes, definitions, } \\
\text { sources and summary }\end{array}$ \\
\hline \multicolumn{7}{|c|}{ Source(s): I-National Statistical institute; II-Bank of Italy; III-Eurostat; IV-General Labour Inspectorate $\quad$ statistics } \\
\hline
\end{tabular}

could be inadequate). As a consequence, one variable (Terth_edlv) has to invert its scale, in order to make this indicator coherent with Cronbach's alpha and Dillon-Goldstein's rho indices. The fact that the scale of this variable is reverted is in agreement with the authors' assumption mentioned in section 3.2. In more detail, changing the direction of the relation is necessary in order to verify that the decrease of the workers' education level is positively correlated with the $U W$.

Table II also shows the satisfactory results of the Principal Component Analysis, which has been performed in order to check the 'one-dimensionality'. The correlation matrix is provided in Table III

It is also important to evaluate if the different blocks are significantly explained by the connected latent variables, and SEM-PLS literature suggests to consider the cross-loadings. The adequate cross-loading values are shown in Table IV, which indicates that positive (and high) loadings exist among the indicators and each latent variables.

4.1.2 Inner and global models. In addition to the measurements that the SEM-PLS literature indicates to assess the quality of the outer model for each block, there are diverse indices useful to validate the 'inner' and the 'global' models. The redundancy index and the coefficient of determination $R^{2}$ represent inner model's indices. Table II indicates satisfactory values of these coefficients. Likewise, the Goodness of Fit (GOF) index can be considered with 
JES
47,2

416

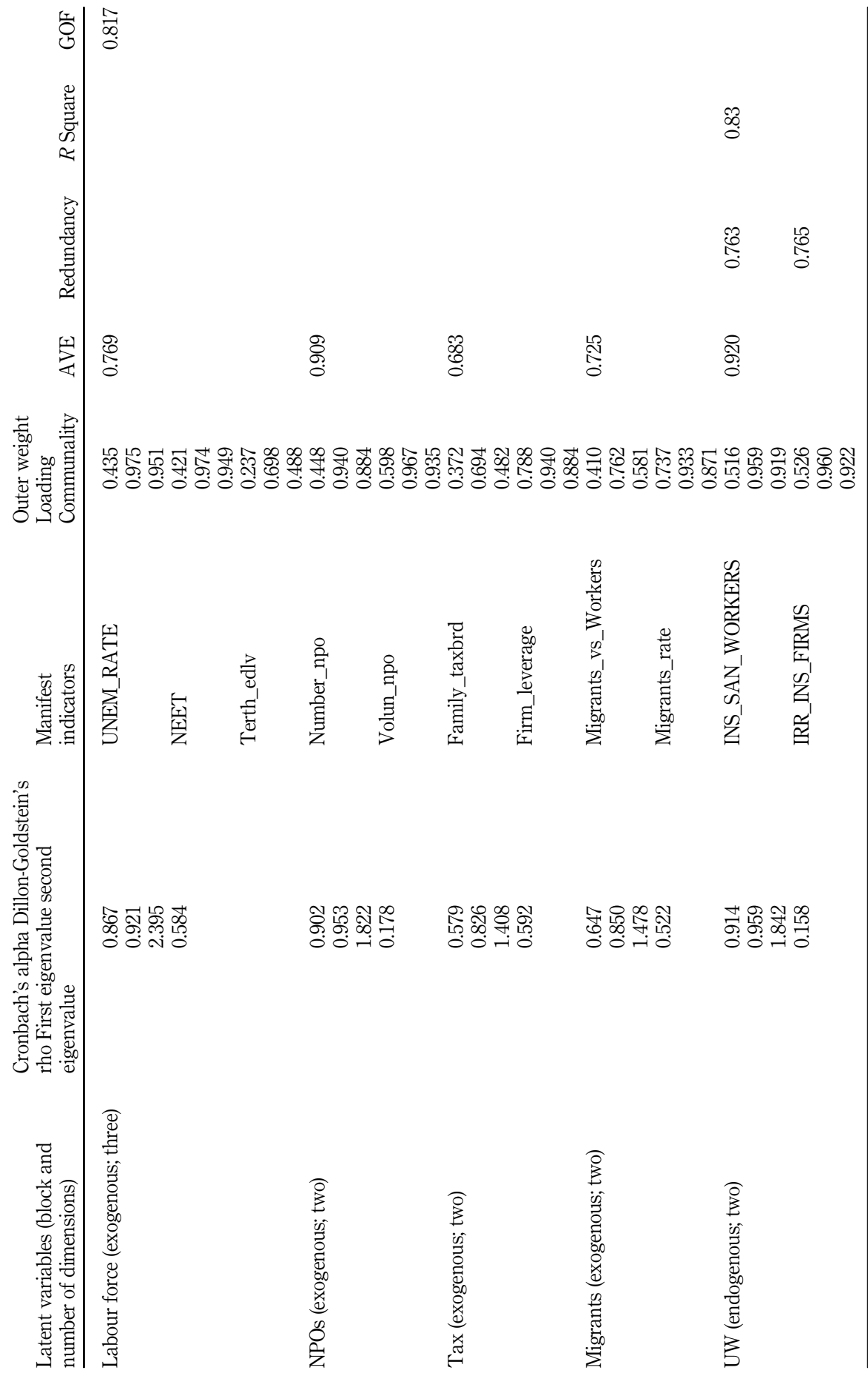

Table II.

Cronbach's alpha,

Dillon-Goldstein's rho,

first two eigenvalues of the indicators'

correlation matrix, and results of the SEM-PLS analysis 
the aim of assessing the global quality of the model. The GoF is equal to 82 percent, greater than the usually recognised threshold (0.7) in the SEM-PLS community.

Table V shows the path coefficients, also known as 'direct effects'. The table also shows the REBUS-PLS results discussed in the next section.

When the standard SEM-PLS approach is performed, analysing the path coefficients, it appears that $U W$ depends on its latent variables expressing the equation in the following form:

$$
\mathrm{UW}=0.374 \text { Labour Force }+0.475 \text { Tax }+0.372 \mathrm{NPOs}-0.271 \text { Migrants }
$$

Table $\mathrm{V}$ indicates that Tax system features appear to be significantly correlated with the $U W$. The remaining coefficients-Labour force, NPOs and Migrants-do not provide significant relationships with the $U W$. Labour force and NPOs have a positive impact, but they are not statistically relevant.

In regard to Migrants, the results do not offer clear evidence of the impact on the $U W$. This coefficient is not statistically significant and has a negative value. This result can be discussed considering several features. Concerning the migrants' involvement in $U W$, Reyneri (1998) noted that-in Italy-in several sectors, such as in agriculture, construction and housekeeping, informal jobs are usually held by regular migrants. Bettin et al. (2019) reported that migrants in Italy are engaged in employment sector not covered by natives (commonly jobs 'unwanted' by Italians). Mingione (2009) explored the Italian industrial districts and emphasized the effect of several different regional policies on migrants' features. These dissimilarities among local policies targeted to the migrants could contribute to explain the no clear evidence emerged from the model. Furthermore, the 'profile' of migrant taxpayers has been examined by Razin et al. (2002), Kirchler et al. (2008) and Kleven et al. (2014). Reyneri (2004) studied the 'migrants with a labour permit' attitude' versus tax compliance, by stressing that they have a major propensity to pay taxes in the host country compared to the native people. International Organization for Migration (IOM, 2017) illustrated several highlights on the migrants' contributions to Italy's welfare. This Report disseminated several estimates of migrants' tax compliance, and highlighted the prevalence of Eastern European (and South American) female workers in the domestic and health care sectors. In addition to these research papers, Torgler (2012) and Williams and Yang (2018) provided a wide discussion on tax compliance in several Eastern European countries, examining in depth the new perspectives, the tax morale features and the implications on the $U W$. In the current article, since ISTAT's data warehouse[8] highlighted that in Italy most migrants are from Eastern Europe, the authors' opinion considers that the high propensity versus tax compliance could depend on the consequences of the non-compliant behaviour (such as leave their host country) which migrants from these countries perceive. The illegal immigration features have not been involved in the present paper. Among other, illegal immigration issues were investigated by Thanos et al. (2011), who noted that an unclear relationship exists between the informal sector and the 'demand' for irregular migrants.

For what it concerns the labour inspections, on which special prominence is dedicated, the analysis provides a positive impact on the $U W$. According to the model's assumptions, their positive correlations confirm the consistency of the analysis. It is also important to underline that the authors stated that one endogenous variable $(U W)$ depends on four exogenous latent variables, but the distinction between exogenous and endogenous variables is not exclusively conceptual (Kaplan, 2004). Even though these kinds of variables are latent variables, the assumption of 'exogeneity' can have significant statistical consequences, since the exogenous determinants can cause fluctuations in the values of endogenous one. Rigdon (2014) discussed on causal (and composite) relationships behind a specific measurement philosophy. Further problems derive from the unclear division between the expressions 'indicators' and 
JES
47,2

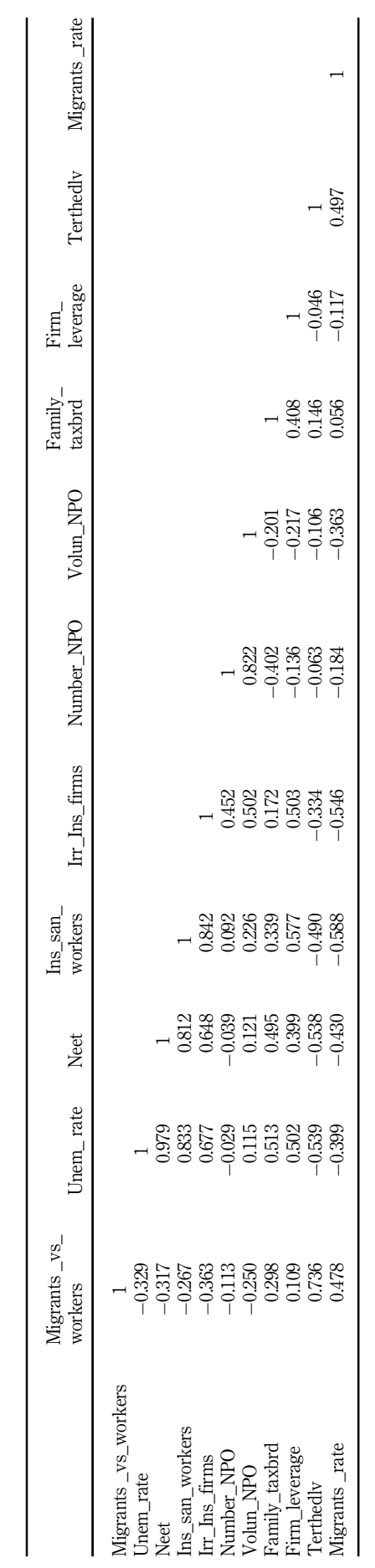

Table III.

Correlation matrix 


\begin{tabular}{|c|c|c|c|c|c|c|}
\hline $\begin{array}{l}\text { Latent variables } \\
\text { Manifest indicators }\end{array}$ & Labour force & NPOs & Tax & Migrants & UW & Examining \\
\hline Unem_rate & 0.975 & 0.055 & 0.587 & -0.429 & 0.786 & $\begin{array}{l}\text { Work } \\
\text { RERI }\end{array}$ \\
\hline Neet & 0.974 & 0.055 & 0.499 & -0.447 & 0.760 & \\
\hline Terth_edlv & 0.698 & 0.092 & -0.018 & -0.668 & 0.429 & \\
\hline Number_npo & -0.014 & 0.940 & -0.257 & -0.182 & 0.285 & \\
\hline Volun_npo & 0.126 & 0.967 & -0.246 & -0.370 & 0.381 & 419 \\
\hline Family_taxbrd & 0.397 & -0.301 & 0.694 & 0.163 & 0.266 & \\
\hline Firm_leverage & 0.397 & -0.191 & 0.940 & -0.042 & 0.562 & \\
\hline Migrants_vs_workers & -0.451 & -0.200 & 0.197 & 0.762 & -0.328 & \\
\hline Migrants_rate & -0.473 & -0.300 & -0.071 & 0.933 & -0.591 & \\
\hline Ins_san_workers & 0.820 & 0.177 & 0.581 & -0.542 & 0.959 & Table IV. \\
\hline Irr_ins_firms & 0.647 & 0.503 & 0.461 & -0.551 & 0.960 & Cross-loadings \\
\hline
\end{tabular}

\begin{tabular}{|c|c|c|c|c|c|c|c|c|}
\hline $\begin{array}{l}\text { Latent } \\
\text { variables }\end{array}$ & $\begin{array}{c}\text { Overall } \\
\text { model path } \\
\text { coefficient }\end{array}$ & $\begin{array}{l}\text { Bootstrap } \\
\text { value }\end{array}$ & $\begin{array}{l}\text { REBUS- } \\
\text { PLS path } \\
\text { coefficient } \\
\text { class } 1\end{array}$ & $\begin{array}{l}\text { REBUS- } \\
\text { PLS path } \\
\text { coefficient } \\
\text { class } 2\end{array}$ & $\begin{array}{l}\text { REBUS- } \\
\text { PLS } \\
\text { GOF } \\
\text { class } 1\end{array}$ & $\begin{array}{l}\text { REBUS- } \\
\text { PLS } \\
\text { GOF } \\
\text { class } 2\end{array}$ & $\begin{array}{l}\text { REBUS- } \\
\text { PLS GQI }\end{array}$ & \\
\hline $\begin{array}{l}\text { LABOUR } \\
\text { FORCE }\end{array}$ & 0.374 & 0.370 & 0.345 & $0.426^{*}$ & 0.841 & 0.903 & 0.879 & \\
\hline NPOs & 0.372 & 0.348 & -0.032 & $0.431 *$ & & & & \\
\hline TAX & $0.475^{*}$ & 0.433 & $0.544^{*}$ & $0.543^{*}$ & & & & \\
\hline MIGRANTS & -0.271 & -0.277 & -0.380 & -0.055 & & & & Table V. \\
\hline \multicolumn{8}{|c|}{ Note(s): $*$ The coefficient is significant at the 0.05 level (2-tailed) } & REBUS-PLS results \\
\hline
\end{tabular}

causal 'determinants'. Despite this, prevalent literature suggests to fix taxation, labour force participation rate, labour market conditions, etc. as causal variables of the informal economy (Herwartz et al., 2013).

Supplementary considerations originate from the possible causal relationships between the manifest variables (such as educational level and/or voluntaries in NPOs) and/or between different constructs (such as voluntaries in NPOs versus Labour force), which can also have an impact on the $U W$. Therefore, considering the relationships stated in the path diagram, since the path coefficients represent the 'direct' effects, it is important to evaluate the 'indirect' effects, which indicate the influence between constructs not directly connected. In fact, these indirect effects indicate the influence of one construct on another construct by taking an 'indirect' path. Consequently, indirect effects must be estimated in order to assess potential causality among the manifest variables in the blocks. In the current research, the 'total' effects (which are the sum of both the direct and indirect effects) are equal to the direct effects, which means that indirect effects are null (not significantly different from zero).

Finally, it is also relevant to underline that:

(1) In addition to the indirect effects, the 'interaction' effects refer to the influence that an additional variable might have on the relationship between an independent and a dependent variable.

(2) In contrast, 'moderating' effects imply the involvement of a variable (such as gender) as a moderator variable, which can changes the strength (and/or the direction) of a relationship between two constructs in the model. 
JES

47,2

420

It is beyond the aim of this paper the development of both the interaction and moderating effects, which become relevant in different contests, by considering the SEM-PLS for comparing groups (Hair et al., 2017).

\subsection{REBUS-PLS}

The REBUS-PLS procedure is based on the GoF index. Among others, Hair et al. (2014) reviewed recent methodological advancements of SEM-PLS dealing with the issue of heterogeneous data structures. One of these techniques refers to the approach proposed by Esposito Vinzi et al. (2008), which is used in the present research. Figure 2 illustrates two different dendrograms of the hierarchical Cluster Analysis (CA), performed by using (a) the 'communality' residuals, and (b) the 'structural' residuals.

Several differences appear between the two diagrams. The dendrogram (a) refers to a CA achieved by using the latent variables' scores. It has the aim of analysing the 'data', and the

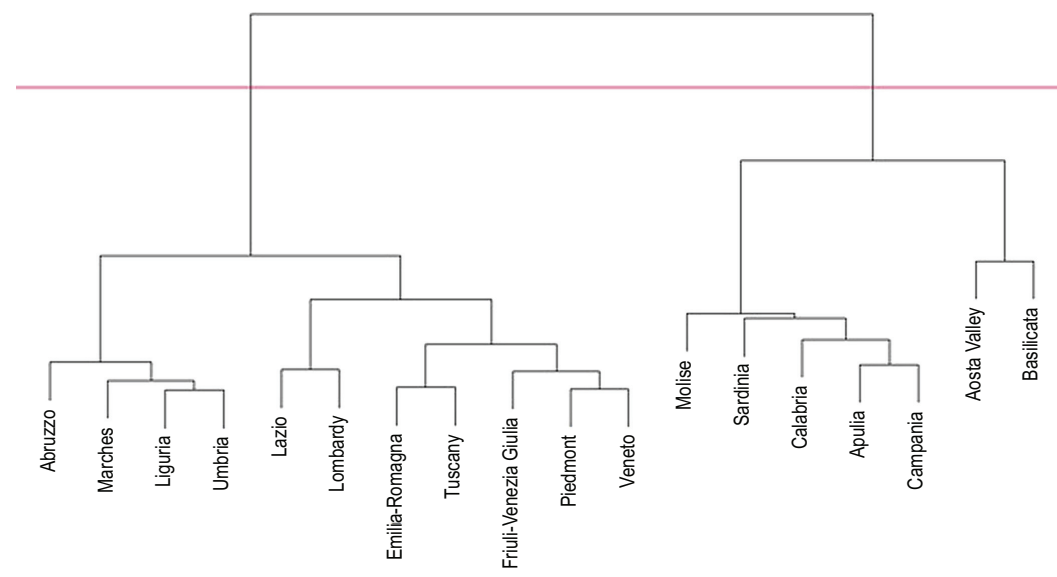

(a)

Figure 2.

Dendrograms obtained throughout a CA on: (a) the latent variables' score; (b) the REBUS procedure' results

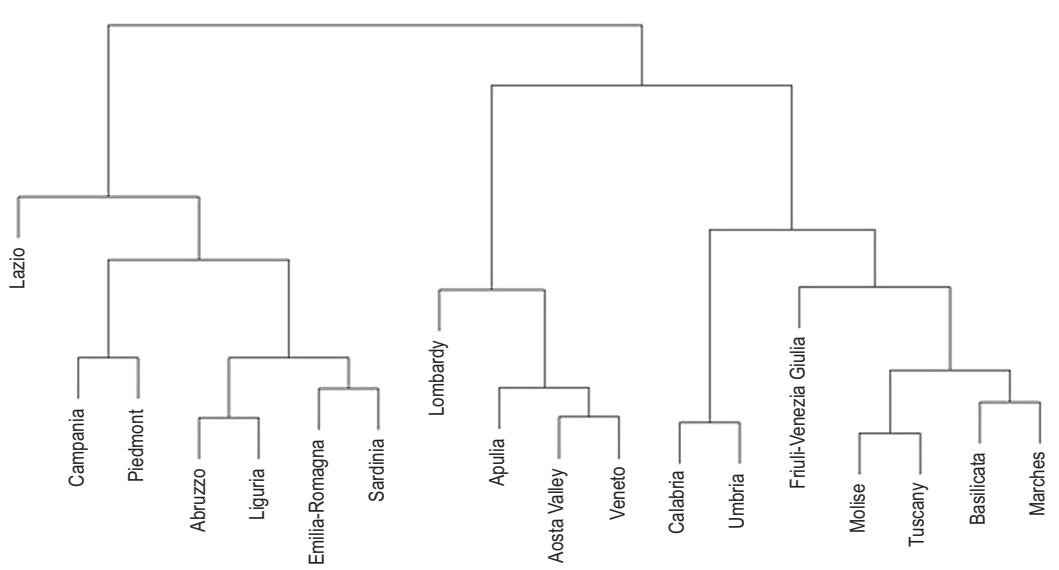

(b) 
results suggest two different classes of regions showing homogeneous behaviour patterns. In order to include the structural relationships among variables, and to achieve differentiated path models, it is necessary to estimate different SEM-PLS procedures for heterogeneous groups of regions. A detailed analysis of the (a) clustering technique is beyond the aim of this research, due to the fact that it is widely debated in different articles (among others, Quintano and Mazzocchi, 2015), and it does not involve the REBUS-PLS. In contrast, in order to study variations in the 'model parameters' of different clusters of observations, a REBUS-PLS procedure can be used. According to the dendrogram (b), the preliminary CA suggests to consider two clusters of regions. The first cluster includes seven regions: Abruzzo, Campania, Emilia-Romagna, Lazio, Liguria, Piedmont, and Sardinia. The second cluster includes eleven regions: Aosta Valley, Apulia, Basilicata, Calabria, Friuli-Venezia Giulia, Lombardy, Marches, Molise, Tuscany, Umbria, and Veneto. At the end of the REBUS-PLS algorithm, none of the regions changed cluster, and the already mentioned Table V shows the corresponding results. This table indicates (path coefficients class one and 2) that two dimensions have relevant impact on the $U W$ in both the clusters: the Tax (which assumes the most important path values), and the Labour force constructs. As assumed by the initial hypothesis, one might expect their positive values. Compared to the coefficients of the overall model (which has only the Tax coefficient as significant at 5 percent confidence level), in the REBUS-PLS procedure, cluster 2 has three significant positive coefficients. In this cluster the Migrants dimension shows a coefficient which has a negative impact on the $U W$, but it is not significant at the mentioned confidence level (the coefficient is almost equal to zero). In the (smaller) cluster one the scenario remains a bit confused, with none of coefficients statistically significant, with the exception of the Tax construct.

Trincera (2011) suggested that a 'reformulated' GoF index (the Group Quality Index -GQI) can be used in the multi-group analysis. Therefore, Table $\mathrm{V}$ indicates both GoF values (calculated in each clusters), and the GQI. The table shows that GQI is equal to 0.879, higher than the GoF value calculated for the global model (0.817), confirming that the local models perform better than the global one. These findings validate that:

(1) An unobserved heterogeneity in the data exists.

(2) The REBUS-PLS allows to optimize the predictive capacity of the model for most of the Italian regions.

\section{Results and conclusions}

This article intends to investigate on $U W$ in Italy considering several determinants of this phenomenon. The authors assume that an unobserved heterogeneity in the data exists, and the results of the model can support policy decisions targeted to the $U W$. Among the numerous determinants of it, several characteristics can be identified as relatively more significant than others: (1) Labour force, (2) Tax system, (3) NPOs, and (4) Migrants. Assuming that the Italian regions are relatively homogeneous, the mentioned features reveal no significant correlations to the $U W$, except for taxes. In contrast, the involvement of the heterogeneity shows that the $U W$ depends on the changes of Labour force, Tax system and NPOs dimensions in 11 out of 18 Italian regions (which belong to the North -South and Centre of Italy). No clear evidence emerges from Migrants feature, which seems to influence negatively the $U W$. At the country level, this negative impact can be interpreted as a careful behaviour of migrants versus tax compliance. The involvement of the dissimilarity results as a decrease of the migrants' impact, and it undertakes almost a neutral effect for the 11 regions cluster. Evidences connected to the labour inspections sustain the assumptions on the effectiveness of the policy efforts targeted 'to manage' the inspectors against the firms involved in the 'most vulnerable' NACE sectors. The inspections represent a significant tool
Examining undeclared work via the REBUS-PLS 
JES

47,2

in order to contribute to curb informality and to encourage accurate wage reporting, even though the labour inspection indicators have been considered as control manifest variables in the model.

Concerning the policy perspective, these findings allow several main theoretical advancements. Firstly, since the statement of the homogeneity in the data can lead to incorrect results, a methodological framework is needed in order to encompass the heterogeneity of the Italian regions. Secondly, since a set of appropriate manifest indicators were obtained by using data from different sources (and by fixing several NACE codes), these manifest dimensions represent potential leverages to avoid that workers participate in the $U W$.

The first above-mentioned theoretical advancement has an important implication for policymakers. In more detail, this result suggests the Government to address specific $U W$ policies calibrating the measurements according to the peculiarities of the specific (and heterogeneous) cluster of regions. At the same time, instead a considering a set of regions, this perspective could aso require addressing policies directed to a single region. De Gregorio and Giordano (2015) and Ciani et al. (2017) highlighted empirical evidences of heterogeneous characteristics of individuals involved in the irregular employment in Italy, and they found several factors strictly related to 'local' economic environment. In order to examine the heterogeneity among the unemployed job seekers, Hynninen (2009) achieved similar conclusions.

The policy implication which derives from the second afore-mentioned advancement refers to the 'selection' of the indicators which should be used as a leverage to tackle the $U W$. Since an efficacious policy aimed to the $U W$ needs to address a number of key challenges, one can consider specific measurements mainly connect to the NEETs, educational skills, NPO sector, non-standard contracts, taxes and migrants. As for the alarming social NEET issue, the European Parliament has recently approved the Youth Guarantee Fund. It consists of a number of initiatives targeted to youth unemployment people and NEETs (European Commission, 2016). The impact of this Found in Italy (and of the recent labour market reform such as the Jobs Act) requires further research. Several factors can modify the NEETs' propensity to look for a job against the condition of being inactive. Therefore, policymakers can consider policies measurements targeted to involve NEETs in training or apprenticeship programs (or creating the conditions for social inclusion, etc.), which can be useful in order to potentially reduce the $U W$. For instance, active labour market policies should be strengthened and better focused on the new labour market entrants. The local (regional) peculiarities need to be consider as well.

Results also show a positive correlation between $U W$ and unemployment rate, confirming recent outcomes of Eurostat (2016) and ILO (2018a). A relevant policy measurement could provide different viable learning opportunities for workers at later stages in their careers. It should be particularly important in the context of a labour market constantly changing, which has an impact on the displacement of workers whose skills are no longer demanded by employers.

The indicator of the workers' level of education confirms a negative correlation with $U W$. Eurostat (2016) highlighted that the level of education is an important factor to address formal and more productive employment, even though it does not represent a guarantee of access. The non-standard forms of employment can offer access to the labour market (and can provide flexibility to both enterprises and workers). Despite this, they can have also distortional effects (such as the voluntarily work) when particularly exposed to the $U W$. Keeping in mind that the share of temporary employment also depends on the liberalization fixed by the National Law, specific policy measurements can (1) modify the requirements of temporary employment of specific categories of workers, (2) mitigate the negative effect of the wider use of temporary contracts, (3) set a limit of the number of successive fixed-term (or project based) contracts (and/or of their maximum cumulative duration). 
In regard to taxes, the results confirm that the reduction of tax burden on the households and firms can reduce the $U W$. European Commission (2017b) described useful recommendations of good practices aimed to support the formal employment throughout the tax leverage. In Italy, a right track could be the recent modifications in the tax rules targeted to increase the decentralization from Central to Regional Governments.

Concerning the remaining relevant migrant issue (and the results that migrants appear to be very careful with tax compliance), it could also be discussed in terms of policy implications. In general, policymakers must sustain-and stimulate-the migrants' propensity versus the tax compliance. In Italy most migrants are from Eastern Europe, and it is important to avoid situations in which Italy (which already attracts migrants due to its geographical exposure and which often is considered as transient country) could attract (legal and illegal) migrants due to its relatively high $U W$. Interesting debates on these features have been proposed by Allasino et al. (2004) and Camacho et al. (2017).

Overall, empirical results show that these indicators have a significant impact on the $U W$ in several Italian regions. In order to avoid that an indicator (for instance the level of education) fails as an indicator of one's involvement in the $U W$, policy measurements could combine several different actions. The present research is obviously subject to certain limitations, such as for those dimensions which have not been included in the analysis. Several issues have been mentioned although not part of the aim of this paper (such as NEETs determinants, over-education, illegal immigration) and several recent (ongoing) initiatives need further research (such as the Youth Guarantee Fund). In addition to them, one might think about the impact on $U W$ of incentives for formal employment, specific (regional) interventions in favour of low-wage earners, and so on. These concerns require extensive exploration, also considering that at the EU level the regular production of regional statistics (mainly at the NUTS2 level) confirm the persistence of significant regional disparities, indicating that the model can be extended to different European countries.

\section{Notes}

1. The Nomenclature of Territorial Units for Statistics (NUTS) 1, two and 3 levels are territorial districts allowing harmonized and comparable socio-economic analyses.

2. The European Statistical Classification of Economic Activities (NACE) refers to the System of National Accounts classification, periodically revised.

3. The informal sector was analysed first by the ILO in 1972. Its international standard definition was adopted during the 15th International Conference of Labour Statisticians (ICLS) in 1993. In 2003 the 17th ICLS reviewed the informal framework in order to include the non-standard types of employment in the formal sector (ILO, 2013a). Since the 'enterprise-based' definition did not consider informal employment entirely, the 17th ICLS adopted a 'job-based' definition in order to include works both within and outside informal sector. The ILO (2015) Recommendation n. 204 (concerning the 'transition from the informal to the formal economy') referred to the guidelines adopted by the 17th ICLS and the further updates (ILO, 2018b).

4. The economic activities belonging to the following seven macro NACE (Rev. 2) categories have been considered: A (Agriculture, forestry and fishing); $\mathrm{C}$ (Manufacturing); $\mathrm{F}$ (Construction); H (Wholesale and retail trade); G (Repair of motor vehicles and motorcycles transportation and storage); I (Accommodation and food service activities); S (Other service activities).

5. The over-skilling refers to overqualified workers who cannot find their proper place in the labour force. European Commission (2017a) estimated that, in recent years, the number of highly-educated workers who are employed in their field of study dramatically decreased. Licata (2015) noted that highly educated Italian people recently relocated to different countries, while in the past they tended to move to the North of Italy. Economic literature provides a controversial interpretation of the
Examining undeclared work via the REBUS-PLS

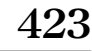


effects of the educational mismatch, and supplementary thoughts derived by the Human Capital (HC) perspective, starting-among others-with the contribution of Schultz (1961).

6. Convention n. 81 referred to industry and commerce. Convention n. 129 referred to agriculture.

7. In Italy there are three kinds of sanctions: administrative, civil and penal. Among others, see Vega and Robert (2013) for an extensive exploration of these features.

8. See more details at http://dati.istat.it/Index.aspx

\section{References}

Allasino, E., Reyneri, E., Venturini, A. and Zincone, G. (2004), "Labour market discrimination against migrant workers in Italy", International Migration Papers, No. 67, available at: https://www.ilo. org/global/topics/labour-migration/publications/WCMS_201593/lang-en/index.htm (accessed 21 December 2018).

Allingham, M.G. and Sandmo, A. (1972), "Income tax evasion: a theoretical analysis", Journal of Public Economics, Vol. 1 Nos 3/4, pp. 323-338.

Becker, J.M., Klein, K. and Wetzels, M. (2012), "Hierarchical latent variable models in PLS-SEM: guidelines for using reflective-formative type models", Long Range Planning, Vol. 45, pp. 359-394.

Benkraiem, R.,.Lahiani, A., Miloudi, A. and Shahbaz, M. (2019), "The asymmetric role of shadow economy in the energy-growth nexus in Bolivia", Energy Policy, Vol. 125, pp. 405-417.

Bettin, G., Bianchi, P., Nicolli, F., Ramacciotti, L. and Rizzo, U. (2019), "Migration, ethnic concentration and firm entry: evidence from Italian regions", Regional Studies, Vol. 53 Nos 1/2, pp. 55-66.

Blackwell, C. (2002), A Meta-Analysis of Tax Compliance Experiments, Working Paper, Charleston College, Charleston, SC.

Boeri, T. and Garibaldi, P. (2002), Shadow Activity and Unemployment in a Depressed Labour Market, CEPR Discussion Papers, No. 3433, CEPR, London.

Bruno, G., Marelli, E. and Signorelli, M. (2014), "The rise of NEET and youth unemployment in EU Regions after the Crisis", Comparative Economic Studies, Vol. 56 No. 4, pp. 592-615.

Camacho, C., Mariani, F. and Pensierosos, L. (2017), "Illegal Immigration and the shadow economy", International Tax and Public Finance, Vol. 24 No. 6, pp. 1050-1080.

Cappariello, R. and Zizza, R. (2010), “Dropping the books and working off the books”, Labour, Vol. 24 No. 2, pp. 139-162.

Charmes, J. (2012), "The informal economy worldwide: trends and characteristics", Margin The Journal of Applied Economic Research, Vol. 6 No. 2, pp. 103-132.

Ciani, E., David, F. and De Blasio, G. (2017), "Local labour market heterogeneity in Italy: estimates and simulations using responses to labour demand shocks", Bank of Italy Working papers, No. 1112, pp. 1-50, available at: https://www.bancaditalia.it/pubblicazioni/temi-discussione/2017/20171112/en_tema_1112.pdf?language_id=1 (accessed 18 December 2018).

De Gregorio, C. and Giordano, A. (2015), The Heterogeneity of Irregular Employment in Italy: Some Evidence from the Labour Force Survey Integrated with Administrative Data, Istat Working papers, No. 1/2015, ISTAT, Rome, pp. 1-21.

De Juan, A., Lasheras, M.A. and Mayo, R. (1994), "Voluntary tax compliant behavior of Spanish income taxpayers", Public Finance, Vol. 49, pp. 90-105.

Dell'Anno, R., Davidescu, A.A. and Balele, N.P. (2018), "Estimating shadow economy in Tanzania: an analysis with the MIMIC approach", Journal of Economic Studies, Vol. 45 No. 1, pp. 100-113.

Di Porto, E. (2011), "Undeclared work, employer tax compliance, and audits", Public Finance Review, Vol. 39 No. 1, pp. 75-102.

Diamantopoulos, A. and Winklhofer, H.M. (2001), "Index construction with formative indicators: an alternative to scale development”, Journal of Marketing Research, Vol. 38 No. 2, pp. 269-277. 
Directorate-General for Internal Policies (2014), "The social and employment situation in Italy", Note per the EMPL Committee, available at: http://www.europarl.europa.eu/RegData/etudes/note/ join/2014/518757/IPOL-EMPL_NT(2014)518757_EN.pdf (accessed 11 December 2018).

Duell, N., Thurau, L. and Vetter, T. (2016), Long-term Unemployment in the EU: Trends and Policies, Bertelsmann Stiftung, Germany.

Esposito Vinzi, V., Trinchera, L., Squillacciotti, S. and Tenenhaus, M. (2008), "REBUS-PLS: a responsebased procedure for detecting unit segments in PLS path modelling", Applied Stochastic Models in Business and Industry, Vol. 24 No. 5 S.I., pp. 439-458.

European Commission (2016), Labour Market Policy - Expenditure and Participants (Data 2014), European Commission, Luxembourg.

European Commission (2017a), Employment and Social Developments in Europe - Annual Review 2017, European Commission, Luxembourg.

European Commission (2017b), Tax Policies in the European Union 2017 Survey, European Commission, Luxembourg.

Eurostat (2014), Essential SNA: Building the Basics, Manuals and Guidelines, Publications Office of the European Union, Luxembourg.

Eurostat (2015), Eurostat Regional Yearbook 2015, Statistical book, Luxembourg.

Eurostat (2016), "Europe 2020 indicators - employment", Statistics explained, available at: ec.europa. eu/eurostat/statistics-explained/index.php/Europe_2020_indicators_-_employment (accessed 15 September 2017).

Eurostat (2017), "Statistics on young people neither in employment nor in education or training", Statistics Explained, available at: ec.europa.eu/eurostat/statistics-explained/index.php/ Statistics_on_young_people_neither_in_employment_nor_in_education_or_training (accessed 17 September 2017).

Eurostat (2018a), Handbook on the Compilation of Statistics on Illegal Economic Activities in National Accounts and Balance of Payments: 2018 Edition, Manuals and Guidelines, Luxembourg.

Eurostat (2018b), "Eurostat regional yearbook: 2018 edition", Statistical book, Luxembourg, available at: https://ec.europa.eu/eurostat/documents/3217494/9210140/KS-HA-18-001-EN-N. pdf/655a00cc-6789-4b0c-9d6d-eda24d412188 (accessed 17 November 2018).

Farr-Wharton, B.S.R., Brown, K., Keast, R. and Shymko, Y. (2015), "Reducing creative labour precarity: beyond network connections", Management Decision, Vol. 53 No. 4, pp. 857-875.

Fasani, M. (2011), "Labour inspection in Italy", LAB/ADMIN Working Document No. 11, available at: https:/www.ilo.org/wcmsp5/groups/public/_ed_dialogue/_lab_admin/documents/publication/ wcms_154063.pdf (accessed 22 November 2018).

Feld, L.P. and Frey, B.S. (2007), "Tax compliance as the result of a psychological tax contract: the role of incentives and responsive regulation”, Law and Policy, Vol. 29 No. 1, pp. 102-120.

Furlong, A. (2006), "Not a very NEET solution”, Work, Employment and Society, Vol. 20 No. 3, pp. 553-569.

Gërxhani, K. (2004), "The informal sector in developed and less developed countries: a literature survey”, Public Choice, Vol. 120 Nos 3/4, pp. 267-300.

Gialis, S. and Leontidou, L. (2014), "Antinomies of flexibilization and atypical employment in Mediterranean Europe: Greek, Italian and Spanish regions during the crisis", European Urban and Regional Studies, Vol. 23 No. 4, pp. 716-733.

GLI - General Labour Inspectorate (2018), “Annual report 2017”, Rome, available at: https:/www. ispettorato.gov.it/it-it/studiestatistiche/Documents/Rapporti\%20annuali/Rapporto-annuale-2017.pdf (accessed 18 March 2018).

Hair, J.F., Ringle, C.M. and Sarstedt, M. (2011), "PLS-SEM: indeed a silver bullet”, Journal of Marketing Theory and Practice, Vol. 19 No. 2, pp. 139-152.
Examining

undeclared

work via the

REBUS-PLS 
Hair, J.F., Sarstedt, M., Ringle, C.M. and Gudergan, S.P. (2017), Advanced Issues in Partial Least Squares Structural Equation Modeling, Sage, Los Angeles.

Hair, J.F., Sarstedt, M., Hopkins, L. and Kuppelwieser, V.G. (2014), "Partial least squares structural equation modeling (PLS-SEM): an emerging tool in business research", European Business Review, Vol. 26 No. 2, pp. 106-121.

Hatton, E. (2015), "Work beyond the bounds: a boundary analysis of the fragmentation of work", Work, Employment and Society, Vol. 29 No. 6, pp. 1007-1018.

Helmke, G. and Levitsky, S. (2004), "Informal institutions and comparative politics: a research agenda", Perspectives on Politics, Vol. 2 No. 4, pp. 725-740.

Herwartz, H., Tafenau, E. and Schneider, F. (2013), "One share fits all? Regional variations in the extent of the shadow economy in Europe”, Regional Studies, Vol. 49 No. 9, pp. 1557-1587.

Hynninen, S.M. (2009), "Heterogeneity of job seekers in labour market matching", Applied Economics Letters, Vol. 16 No. 18, pp. 1819-1823.

ILO (2013a), Measuring Informality: A Statistical Manual on the Informal Sector and Informal Employment, International Labour Office - Department of Statistics, Geneva.

ILO (2013b), "Labour inspection and undeclared work in the EU", Working Document No 29, Geneva, avalailable at https://www.ilo.org/labadmin/info/pubs/WCMS_220021/lang-en/index.htm (accessed 18 December 2018).

ILO (2014), "Transitioning from the informal to the formal economy", International Labour Conference - 103rd Session - Report V, Geneva, International Labour Office, available at: www.ilo.org/ wcmsp5/groups/public/—ed_norm/—relconf/documents/meetingdocument/wcms_218128.pdf (accessed 29 September 2017).

ILO (2015), "Recommendation 204 concerning the transition from the informal to the formal economy", Adopted by the Conference at its One Hundred and Fourth Session, Geneva, 12 June, International Labour Office, Geneva, available at: https:/www.ilo.org/wcmsp5/groups/ public/_ed_norm/_relconf/documents/meetingdocument/wcms_377774.pdf (accessed 15 December 2018).

ILO (2016), "Final Report - LFS Pilot Studies Analysis Workshop", International Labour Office, Geneva, available at: www.ilo.org/wcmsp5/groups/public/—dgreports/—stat/documents/ publication/wcms_541491.pdf (accessed 28 September 2017).

ILO (2018a), "Informality and non-standard forms of employment", Paper Prepared for the G20 Employment Working Group meeting, available at: https://www.ilo.org/wcmsp5/ groups/public/—dgreports/—inst/documents/publication/wcms_646040.pdf (accessed 15 December 2018).

ILO (2018b), "Guidelines Concerning Statistics of International Labour Migration”, 20th International Conference of Labour Statisticians, ICLS/20/2018/Guidelines, Department of Statistics, Geneva, available at: https:/www.ilo.org/wcmsp5/groups/public/—dgreports/—stat/documents/ meetingdocument/wcms_648922.pdf (accessed 22 December 2018).

ILO (2018c), "ILO global estimates on international migrants workers: results and methodology", 2nd ed., Department of Statistics, Geneva, available at: https:/www.ilo.org/wcmsp5/groups/ public/—dgreports/—dcomm/_publ/documents/publication/wcms_652001.pdf (accessed 23 December 2018).

IOM - International Organization for Migration (2017), "Migrants' contributions to Italy's welfare", IOM Italy Briefing, No. 2, Geneva, pp. 1-7, available at: https:/italy.iom.int/sites/default/files/ documents/IOM_Italy_Briefing_02_Oct2017_Migrants\%20contributions.pdf (accessed 17 December 2018).

ISTAT (2018), “Annual report”, Rome, available at: https://www.istat.it/storage/rapporto-annuale/ 2018/Rapportoannuale2018.pdf (accessed 18 December 2018).

Kaplan, D. (2004), "On exogeneity", in Kaplan, D.W. (Ed.), The Sage Handbook of Quantitative Methodology in Social Sciences, Sage, Newbury Park, CA, pp. 407-421. 
Kirchler, E., Hoelzl, E. and Wahl, I., (2008), "Enforced versus voluntary tax compliance: the 'slippery slope' framework", Journal of Economic Psychology, Vol. 29, pp. 210-225.

Kleven, H.J., Landais, C., Saez, E. and Schultz, E. (2014), "Migration and wage effects of taxing top earners: evidence from the foreigners' tax scheme in Denmark", The Quarterly Journal of Economics , Vol. 129 No. 1, pp. 333-378.
Examining

undeclared work via the REBUS-PLS

Licata, D. (2015), Rapporto Italiani Nel Mondo 2015, Fondazione Migrantes, Tau Editrice, Milan, Italy.

Maroukis, T., Gmaj, K. and Iglicka, K. (2011), "Irregular migration and informal economy in Southern and Central-Eastern Europe: breaking the vicious cycle?", International Migration, Vol. 49 No. 5, pp. 129-156.

Martin, J.P., Martin, S. and Quintini, G. (2007), The Changing Nature of the School-To-Work Transition Process in OECD Countries, IZA DP No. 2582, Bonn.Germany.

Mazzolini, G., Pagani, L. and Santoro, A. (2017), "The deterrence effect of real-world operational tax audits", DEMS Working paper series No. 359, Department of Economics, Management and Statistics, University Bicocca, Milan, pp. 1-51, doi: 10.2139/ssrn.2914374.

McCollum, D. and Findlay, A. (2015), "Flexible workers for 'flexible' jobs? The labour market function of A8 migrant labour in the UK", Work, Employment and Society, Vol. 29 No. 3, pp. 427-443.

Mingione, E. (2009) "Family, welfare and districts: the local impact of new migrants in Italy", European Urban and Regional Studies, Vol. 16 No. 3, pp. 225-236.

Murphy, K. (2005), "Regulating more effectively: the relationship between procedural justice, legitimacy, and tax non-compliance", Journal of Law and Society, Vol. 32, pp. 562-589.

Nelson, M.K. and Smith, J. (1999), Working Hard and Making Do: Surviving in Small Town America, University of California Press, Berkeley, California.

OECD (2003), Measuring the Non-observed Economy: A Handbook, OECD Publishing, Paris.

OECD (2010), Understanding and Influencing Taxpayers' Compliance Behaviour, OECD Publishing, Paris.

OECD (2012), Reducing Opportunities for Tax Non-compliance in the Underground Economy, OECD Publishing, Paris.

OECD (2016), Society at a Glance 2016- Social Indicators -a Spotlight on Youth, OECD Publishing, Paris.

Olivieri, F. (2012), "Migrants as activist citizens in Italy: understanding the new cycle of struggles", Citizenship Studies, Vol. 16 Nos 5/6, pp. 793-806.

Piore, M.J. and Schrank, A. (2008), "Toward managed flexibility: the revival of labour inspection in the Latin world", International Labour Review, Vol. 147 No. 1, pp. 1-23.

Pires, R. (2008), "Promoting sustainable compliance: styles of labour inspection and compliance outcomes in Brazil", International Labour Review, Vol. 147 Nos 2/3, pp. 199-229.

Quintano, C. and Mazzocchi, P. (2013), "The shadow economy beyond the European public governance", Economic Systems, Vol. 37 No. 4, pp. 650-670.

Quintano, C. and Mazzocchi, P. (2015), "The shadow economy as a higher order construct inside European governance", Journal of Economic Studies, Vol. 42 No. 3, pp. 477-498.

Razin, A., Sadka, E. and Swagel, P. (2002), "Tax burden and migration: a political economy theory and evidence", Journal of Public Economics, Vol. 85 No. 2, pp. 167-190.

Reinartz, W.J., Haenlein, M. and Henseler, J. (2009), "An empirical comparison of the efficacy of covariance-based and variance-based SEM", International Journal of Market Research, Vol. 26 No. 4, pp. 332-344.

Renooy, P. (2007), "Undeclared work: a new source of employment?", International Journal of Sociology and Social Policy, Vol. 27 Nos 5/6, pp. 250-256.

Reyneri, E. (1998), "The role of the underground economy in irregular migration to Italy: cause or effect?", Journal of Ethnic and Migration Studies, Vol. 24 No. 2, pp. 313-331. 
Reyneri, E. (2004), "Immigrants in a segmented and often undeclared labour market", Journal of Modern Italian Studies, Vol. 9 No. 1, pp. 71-93.

Richardson, M. and Sawyer, A. (2001), "A taxonomy of the tax compliance literature: further findings, problems and prospects", Australian Tax Forum, Vol. 16 No. 2, pp. 137-320.

Rigdon, E.E. (2014), "Comment on Improper use of endogenous formative variables", Journal of Business Research, Vol. 67 No. 2, pp. 2800-2802.

Sassen, S. (1997), Informalization in Advanced Market Economies, Development Discussion Paper 20, International Labour Office - Development Policies Department, Geneva.

Schneider, F. and Enste, D.H. (2013), The Shadow Economy: An International Survey, 2nd ed., Cambridge University Press, Cambridge.

Schneider, F. and Williams, C.C. (2013), The Shadow Economy, Institute of Economic Affairs, London.

Schultz, W.T. (1961), "Investment in human capital", American Economic Association, Vol. 51, pp. 1-17.

Singla, A., Ahuja, I.S. and Sethi, A.S. (2018), "Validation of demand pull strategies for accomplishing sustainable development in manufacturing organizations through structural equation modelling”, Management Decision, Vol. 56 No. 5, pp. 1135-1156.

Slemrod, J. and Weber, C. (2012),"Evidence of the invisible: toward a credibility revolution in the empirical analysis of tax evasion and the informal economy", International Tax and Public Finance, Vol. 19 No. 1, pp. 25-53.

Thanos, M., Krystyna, I. and Katarzyna, G. (2011), "Irregular migration and informal economy in southern and central- eastern Europe: breaking the vicious cycle?", International Migration, Vol. 49 No. 5, pp. 129-156.

Torgler, B. (2012), "Tax morale, eastern Europe and European enlargement", Communist and PostCommunist Studies, Vol. 45, pp. 11-25.

Trinchera, L. (2011), "Assessment of latent class detection in PLS path modelling: a simulation study to evaluate the group quality index performance", in Fichet, B., Piccolo, D., Verde, R., Vichi, M. et al. (Eds), Classification and Multivariate Analysis for Complex Data Structure, Springer, Berlin, pp. 281-289.

Vega, M.L. and Robert, R. (2013), "Labour inspection sanctions: law and practice of national labour inspection systems", ILO, Working Document, No. 26, Geneva, available at: http:// adapt.it/adapt-indice-a-z/wp-content/uploads/2013/08/labour_inspection_sanctions_ilo_2013.pdf (accessed 3 December 2018).

Vos, S., Breesch, D. and Scheerder, J. (2012), "Undeclared work in non-profit sports clubs: a mixed method approach for assessing the size and motives", International Journal of Voluntary and Non Profit Organizations, Vol. 23 No. 4, pp. 846-869.

Webb, J.W., Tihanyi, L., Ireland, R.D. and Sirmon, D.G. (2009), "You say illegal, I say legitimate: entrepreneurship in the informal economy", Academy of Management Review, Vol. 34 No. 3, pp. 492-510.

Weil, D. (2008), “A strategic approach to labour inspection”, International Labour Review, Vol. 147 No. 4, pp. 350-375.

Williams, C.C. and Bezeredi, S. (2018a), "Explaining and tackling the informal economy: a dual informal labour market approach", Employee Relations, Vol. 40 No. 5, pp. 889-902.

Williams, C.C. and Bezeredi, S. (2018b), "An institutional theory of informal entrepreneurship: some lessons from FYR Macedonia”, Journal of Developmental Entrepreneurship, Vol. 23 No. 3. 1850019. ISSN 1084-9467.

Williams, C.C. and Lansky, M.A. (2013), "Informal employment in developed and developing economies: perspectives and policy responses", International Labour Review, Vol. 152, pp. 355-380.

Williams, C.C. and Padmore, J. (2013), "Envelope wages in the European union”, International Labour Review, Vol. 152 Nos 3-4, pp. 411-430. 
Williams, C.C. and Shahid (2014), "Informal entrepreneurship and institutional theory: explaining the varying degrees of (in)formalization of entrepreneurs in Pakistan", Entrepreneurship and Regional Development: International Journal, Vol. 1, pp. 1-25.

Williams, C.C. and Windebank, J. (2005), "Eliminating undeclared work: beyond a deterrence approach”, Journal of Economic Studies, Vol. 32 No. 5, pp. 435-449.

Williams, C.C. and Yang, J. (2018), "Evaluating competing perspectives towards undeclared work: some lessons from Bulgaria”, Journal of Contemporary Central and Eastern Europe, Vol. 26, Nos 2-3, pp. 247-265.

Williams, C.C., Horodonic, I.A. and Windebank, J. (2016) . Explaining participation in the informal economy: a purchaser perspective, International Journal of Social Economics, Vol. 44 No. 11, pp. 1421-1436.

Williams, C.C., Windebank, J., Baric, M. and Nadin, S. (2013), "Public policy innovations: the case of undeclared work", Management Decision, Vol. 51 No. 6, pp. 1161-1175.

Woolfson, C. (2007a), "Pushing the envelope: the 'informalization' of labour in post-communist new EU member states", Work, Employment and Society, Vol. 21 No. 3, pp. 551-564.

Woolfson, C. (2007b), "Labour standards and migration in the New Europe: post-communist legacies and perspectives”, European Journal of Industrial Relations, Vol. 13 No. 2, pp. 199-218.

\section{Appendix}

\section{Inner and outer models}

Each PLS path model consists of an inner and of an outer model. The inner model shows the relationships (paths) among the latent constructs. The outer model refers to the (unidirectional) predictive relationships among each latent construct and its associated observed indicators. There are two different measurement models: the first one refers to the exogenous latent variables, which involves those constructs that explain other constructs in the model; the second refers to the endogenous latent variables, which describes latent target constructs that can be explained by other constructs via the structural model relationships (Hair et al., 2017). In the outer model, 'multiple' relations are not permitted; therefore, each indicator is associated with a single latent construct (Hair et al., 2011). The path model also specifies the 'direction' of the relationships, since SEM-PLS can handle both 'reflective' measurement model (changes in the latent construct cause changes in manifest variables) and 'formative' model (changes in the indicators determine changes in the value of the latent construct). The reflective-formative model considered in the present research is widely discussed by Becker $e t$ al. (2012). An extensive evaluation of situations in which a construct is adequately fixed has been also proposed by Diamantopoulos and Winklhofer (2001).

\section{Principal Component Analysis and one-dimensionality}

If the first eigenvalue of the correlation matrix is higher than one (and the second eigenvalue is smaller than one) the block can be considered as one-dimensional.

\section{Cross-loadings}

According to the loading definition (which represents the correlation between a latent variable and its indicators), the cross-loading considers the indicators compared to all the latent variables. The crossloading analysis allows to verify that (in each block) the shared variance between a latent variable and its indicators is larger than the shared variance in different blocks.

\section{SEM-PLS model validation}

As for the outer model, the coefficient of determination $R^{2}$ suggests that the variance of the dependent (endogenous) latent variable $(U W)$ is sufficiently explained by its four independent latent variables. As for the inner model, the 'communality' measurement considers the shared variance between a latent variable and its indicators. Its refers to the squared of the loading value and the fifty percent corresponds to a sufficiently good threshold. The 'redundancy indices' are 
calculated only for the endogenous construct, and the two high values reveal a corresponding high ability of the model to make prediction. The usage of a shared criterion to measure the overall quality of the model in the SEM-PLS context has been widely debated in the recent literature. The GoF index (greater than 0.7) can be considered with the aim of assessing the 'global' quality of the model. The non-parametric tests can be used in order to statistically validate the model. In fact, the non-parametric bootstrap procedure is suitable with the aim of providing bootstrap confidence intervals for the parameters. Nevertheless, different resampling procedures, such as blindfolding and Jacknife can also be used.

\section{About the authors}

Claudio Quintano is Emeritus Professor of Economic Statistics. E-mail: claudio.quintano@ uniparthenope.it. Orcid ID 0000-0001-8315-8476

Paolo Mazzocchi is an Associate Professor of Economic Statistics. E-mail: paolo.mazzocchi@ uniparthenope.it. Orcid ID 0000-0002-6632-314X Paolo Mazzocchi is the corresponding author and can be contacted at: paolo.mazzocchi@uniparthenope.it

For instructions on how to order reprints of this article, please visit our website: 